\title{
Mean platelet volume may not be a risk factor in patients with cerebral venous thrombosis
}

\author{
Cengiz Beyann ${ }^{1}$, Esin Beyan²
}

${ }^{1}$ Ufuk University Faculty of Medicine, Department of Hematology, Ankara;

${ }^{2}$ University of Health Sciences, Kecioren Training and Research Hospital, Department of Internal Medicine, Ankara, Turkey

Corresponding author: Cengiz Beyan, MD, Prof. Ufuk University Faculty of Medicine, Department of Hematology, Çankaya, Ankara, Turkey

E-mail: cengizbeyan@hotmail.com

Received/Accepted: March 16, 2018 / April 17, 2018

Conflict of interest: There is not a conflict of interest.

\section{Dear Editor,}

We read with a great interest the article of Bolayir et al. about the role of mean platelet volume (MPV), platelet distribution width (PDW) and platelet / lymphocyte ratio in development of cerebral venous thrombosis $(\mathrm{CVST})^{1}$. They suggested that MPV and PDW values were new independent risk factors for CVST development. We would like to comment on the results of this study.

Firstly, the authors claimed that MPV and PDV were indicators of platelet function. It is a critical issue that the platelet parameters including MPV and PDW are not accepted as the tests of platelet function. The gold standard test for platelet function is the turbidimetric platelet aggregometry and the relationship between platelet parameters including MPV and PDW and the platelet aggregation results usage of turbidimetric platelet aggregometry were not shown in various studies ${ }^{2}$. Actually, these parameters are related with platelet production not platelet function.

Up to now, the measurement of MPV has not been yet standardized ${ }^{3}$. The timing is very important issue for measurement of the MPV. Jackson and Carter reported the effect of ethylenediaminetetraacetic acid (EDTA) as an anticoagulant on platelet counting ${ }^{4}$. The MPV increases with EDTA depending on the measurement time after venipuncture. This increment generally occurs up to $30 \%$ within first 5 minutes of exposure to EDTA and then proceeds with extra $10-15 \%$ over the following 2 hours. A meta-analysis study that was performed in published MPV studies indexed PubMed showed that the measurement times between 15 minutes and 2 hours was significantly different from the measurement times of shorter than 15 minutes and longer than 2 hours 5 . The MPV measurements varied up to $12.5 \%$ in these studies and this difference was specified as $2-50 \%$ by the review of Jackson and Carter ${ }^{4,5}$. Briefly, the results might be affected considerably due to the measurement time after venipuncture as an important preanalytic variable in this retrospective study. Therefore, the reliability of MPV results of this study was questionable.

Also, the various techniques of different instruments for measuring the complete blood count lead to variable MPV results. MPV discrepancies up to $40 \%$ were reported with comparison of the instruments. The MPV measurements varied up to $17.8 \%$ by the instrument and maximum deviation together with the difference of instruments used plus MPV measurement times was up to $27.7 \%$ in metaanalysis study ${ }^{5}$. The authors specified that Mindray BC-6800 device was used for analysis of the blood samples in their study included the data between January 2008 and September 2016. Because the license year of this automated blood counter was 2013, it must be used other instrument/s in the study, too.

As a result, higher MPV might be originated from the standardization errors of measurement technique rather than the occurrence of CVST.

Key words: Intracranial sinus thrombosis, mean platelet volume, predictive value of tests, venous thrombosis 


\section{REFERENCES}

1. Bolayır A, Gokce SF. The role of mean platelet volume, platelet distribution width and platelet / lymphocyte ratio in development of cerebral venous thrombosis. J CM 2017; 39: 683-91. URL:

http://dergipark.gov.tr/223/issue/32356/36933 6

2. Beyan $C$, Kaptan K, Ifran A. Platelet count, mean platelet volume, platelet distribution width, and plateletcrit do not correlate with optical platelet aggregation responses in healthy volunteers. J Thromb Thrombolysis 2006; 22: 161-4. URL: https://www.ncbi.nlm.nih.gov/pubmed/171112 02

3. Noris P, Melazzini F, Balduini CL. New roles for mean platelet volume measurement in the clinical practice? Platelets 2016; 27: 607-12. URL:

https://www.ncbi.nlm.nih.gov/pubmed/27686 008

4. Jackson SR, Carter JM. Platelet volume: laboratory measurement and clinical application. Blood Rev 1993; 7: 104-13. URL: https://www.ncbi.nlm.nih.gov/pubmed/83696 59

5. Beyan C, Beyan E. Were the measurements standardized sufficiently in published studies about mean platelet volume? Blood Coagul Fibrinolysis 2017; 28: 234-6. URL: https://www.ncbi.nlm.nih.gov/pubmed/27388 283 